\title{
El vínculo social en Nueva Granada 1780-1816*
}

\section{ISIDRO VANEGAS USECHE}

Profesor asociado de la Universidad Pedagógica y Tecnológica de Colombia (Colombia). Correo electrónico: isidro.vanegas@uptc.edu.co. El autor es Sociólogo de la Universidad Nacional de Colombia (Colombia), magíster en DEA d'bistoire Contemporaine Des Mondes Etrangerelkes y doctor en Historia de la Universite de Paris I (Pantheon-Sorbonne). Entre sus publicaciones recientes tenemos: "El pedestal erróneo para un prócer. Antonio Nariño y la revolución neogranadina", en Revista de Estudios Históricos No. 63 (2016) y "Los inicios del régimen democrático en la Nueva Granada: la noción y sus dilemas (1790-1830)", en Historia Crítica No. 58 (2015). Entre sus temas de interés están historia de la democracia en Colombia, espacios, instituciones y referentes de lo público y la revolución como experiencia de lo político.

Recibido: 19 de septiembre de 2014

Aprobado: 12 de enero de 2015

Modificado: 15 de febrero de 2015

Artículo de investigación científica

DOI: http://dx.doi.org/10.15648/hc.28.2016.2

* $\quad$ Este artículo forma parte del proyecto: "Historia de Boyacá siglo XIX. Primera etapa" financiado por Dirección de Investigaciones de la Universidad Pedagógica y Tecnológica de Colombia (Colombia).

Esta publicación está bajo una licencia Creative Commons Reconocimiento-NoComercial 4.0 


\title{
El vínculo social en Nueva Granada 1780-1816
}

\section{Resumen}

El vínculo social es una noción que remite tanto a la experiencia que los hombres construyen de su coexistencia como a la representación que se hacen de ella. Este artículo muestra cómo la Revolución Neogranadina de la década de 1810 constituyó un punto de ruptura del vínculo social tejido por los habitantes del Nuevo Reino de Granada. En el orden monárquico, este se había caracterizado por estar fundado en una desigualdad jerárquica; por estar investido fuertemente de sacralidad, sujeto al imperativo de la incorporación, y preceder al individuo; rasgos todos que encontraban su síntesis en la figura del monarca. Con la revolución, emerge un nuevo tipo de vínculo social cuyos atributos centrales consisten en su fundamentación en el principio de la igualdad, su carácter mundano, la necesidad que tiene del consentimiento, así como su obligatoriedad.

Palabras clave: vínculo social, monarquía, Nueva Granada, revolución, democracia.

\section{The social bond in Nueva Granada 1780-1816}

\begin{abstract}
The social bond is a concept that refers both to the experience men build from their coexistence as the representation they make of it. This article shows how the Neogranadina Revolution of the 1810 s was a breaking point of the social bond planned by the inhabitants of the Nueva Granada Kingdom. In the monarchy system, characterized by a hierarchical inequality and a strong sense of sacredness, subject to the imperative of incorporation, and preceding the individual; all traits that based their synthesis in the monarch's figure. With the revolution, a new type of social bond emerges, whose core attributes consist of its foundation on the principle of equality, their worldly character, the need for consent, as well as its obligation.
\end{abstract}

Key words: social bond, monarchy, Nueva Granada, revolution, democracy.

\section{O vínculo social em Nova Granada 1780-1816}

\section{Resumo}

O vínculo social é uma noção que remite tanto à experiência que os homens constroem da sua coexistência quanto à representação que eles fazem dela. Este artigo mostra 
como a revolução neogranadina da década de 1810 constituiu um ponto de desligamento do vínculo social construído pelos habitantes do Novo Reino de Granada. Na ordem monárquica, este tinha se caracterizado por estar fundado em uma desigualdade hierárquica; por estar fortemente investido em sacralidade, sujeito ao imperativo da incorporação, e preceder ao indivíduo; todos esses traços encontravam sua sínteses no monarca. Junto à revolução emerge um novo tipo de vínculo social cujos atributos centrais consistem na fundamentação do princípio de igualdade, o caráter secular, a necessidade que há do consentimento, assim como a sua obrigatoriedade.

Palavras chave: vínculo social, monarquia, Nova Granada, revolução, democracia.

\section{Le lien social en Nouvelle Grenade (1780-1816)}

\section{Résumé}

Le lien social est une notion qui renvoie tant à l'expérience que les hommes construisent de leur coexistence qu'à la représentation qu'ils s'en font. Cet article montre comment la Révolution Néo-grenadine de la décennie de 1810 constitua un point de rupture du lien social tissé par les habitants du Royaume de la Nouvelle Grenade. Dans l'ordre monarchique, celui-ci s'était caractérisé par son fondement sur l'inégalité hiérarchique ; par son fort penchant vers la sacralité, assujetti à l'impératif de l'incorporation, et par précéder à l'individu ; des traits qui rencontraient tous leur synthèse dans la figure du monarque. Dans la révolution, on assiste à l'émergence d'un nouveau type de lien social dont les attributs principaux consistent en son fondement sur le principe d'égalité, son caractère mondain, son besoin de consentement, ainsi que son caractère obligatoire.

Mots clés: lien social, monarchie, Nouvelle Grenade, révolution, démocratie.

Las revoluciones conllevan un cambio sustancial del vínculo social, esto es, una mudanza en la experiencia que los hombres hacen de su coexistencia y en el desciframiento que elaboran de ella. En 1792 Henry Bancal escribió que la Revolución Francesa había roto las cadenas que ataban al pueblo pero al costo de sumirlo en un estado anti-natural, pues la consumación de esa ruptura había precisado la destrucción del "vínculo social” y había 
llevado a la profundización de la tiranía ${ }^{1}$. Un sentimiento similar al de ese oscuro diputado a la Convención Nacional expresaron pocos años después algunos publicistas neogranadinos cuando trataron de comprender la naturaleza de aquella revolución. Vieron en ella espantosas amenazas, lo cual agudizó su convicción de que la monarquía española, su monarquía, era imprescindible para el desarrollo de un vínculo social armónico y dotado de sentido, puesto que era la sola comunidad política la que podía paliar lo defectuoso del género humano tras su expulsión del paraíso.

Pero la monarquía no simplemente generó adhesiones intelectuales como estas -que por lo demás fueron generalizadas-, sino que fue el espacio en medio del cual se levantó el edificio social neogranadino del periodo anterior a su revolución. Este acontecimiento de la década de 1810, justamente, vino a derribar aquella construcción y a inscribir el vínculo social en las coordenadas del régimen democrático que entonces inició ${ }^{2}$. Se trató, como lo mostraré en este trabajo, de un cambio fundamental para los neogranadinos, como ellos lo percibieron en su momento con esperanza o con angustia. Este artículo incluye una síntesis de los fundamentos y los rasgos del vínculo social en uno y otro momento, pero prescinde de detalles con respecto a los eventos en medio de los cuales tuvo lugar tal cambio.

\section{El VíNCULO SOCIAL EN EL ORDEN MONÁRQUiCO}

Si se desea comprender la manera como se concibió y se desarrolló el vínculo social en la Nueva Granada del periodo anterior a su revolución, es preciso dejar de lado la definición de este como periodo colonial. Por más difundida que esté, dicha designación borra elementos esenciales de la vida de los neogranadinos, como su orgullo de pertenecer a la nación es-

1 Henry Bancal, Du nouvel ordre social (París: Imprimerie du Cercle Social, 1792), 7. En 1829 Lamennais escribió que el rasgo distintivo de su época consistía en "la abolición absoluta de todo vínculo social”, tarea que había adelantado triunfalmente la Revolución Francesa, o la teoría filosófica moderna, que venían a ser lo mismo. Félicité Robert de Lamennais, Des progrès de la Révolution et de la guerre contre l'Église (Lovaina: Vanlinthout et Vandenzande, 1829), 5.

2 Véase al respecto Isidro Vanegas, "Los inicios del régimen democrático en la Nueva Granada: la noción y sus dilemas (1790-1830)”, Historia Crítica No. 58 (2015): 57-75. 
pañola y su generalizada veneración por el monarca. Esta figura de poder y autoridad, en efecto, logró el rol central en esa sociedad y la determinó de tal manera que se debe considerar aquel como un orden monárquico, en el doble sentido que el reino neogranadino estuvo inscrito en el imperio y que los neogranadinos se reconocieron a sí mismos como súbditos ${ }^{3}$. Esto significó que el vínculo social fue tejido tratando de plasmar en él las virtudes superlativas que el rey idealmente encarnaba y protegía. De manera que el vínculo social en aquel periodo, y particularmente durante los reinados de Carlos III y Carlos IV, se caracterizó por estar fundado en una desigualdad jerárquica, por estar fuertemente investido de sacralidad, por estar sujeto al imperativo de la incorporación y preceder al individuo. Mostraré enseguida esos rasgos.

En primer lugar, el vínculo social estuvo basado en una desigualdad jerárquica. Esta desigualdad, consustancial al orden monárquico, se filtró en todos los espacios, determinó todas las relaciones, sirvió de fundamento a todas las instituciones. Del vigor que tuvo nos habla el tipo de trato que se dieron los grupos sociales y los núcleos de población, la manera como fueron utilizados los espacios públicos (la iglesia, la escuela, la calle), la disposición de las celebraciones sacras y profanas, los patrones que siguió la vida doméstica. Para refrendar aquel principio de desigualdad, en la segunda mitad del siglo XVIII se entablaron multitud de pleitos mediante los cuales se buscaba probar la pureza de sangre u obtener el reconocimiento del título de "don". Con igual objeto se iniciaron numerosos disensos matrimoniales, en los que generalmente se trató de comprobar que uno de los futuros cónyuges carecía del requisito de la igualdad de condición, como lo alegó un sujeto de Medellín al invocar una Real pragmática, "que prohíbe, y desaprueba los Matrimonios desiguales, por las perniciosas consecuencias, que de ellos resulta, al Estado, y a las familias"5. Así, resultaba

3 Un desarrollo de este planteamiento en Isidro Vanegas, La Revolución Neogranadina (Bogotá: Ediciones Plural, 2013).

4 Jaime Jaramillo, Ensayos de historia social, T. I (Bogotá: Tercer Mundo/Uniandes, 1994), 159-216.

5 Disenso matrimonial interpuesto por Nicolás de Cárdenas, Medellín, mayo de 1793, en Archivo General de la Nación (AGN), Colonia, Genealogías, rollo 13, f. 624r. Un estudio general sobre la cuestión en Ann Twinam, Vidas públicas, secretos privados. Género, honor, sexualidad e ilegitimidad en la Hispanoamérica colonial (Buenos Aires: Fondo de Cultura Económica, 2009). 
normal que la precedencia social pudiera ser reclamada también desde la cárcel, como lo hizo en 1800 un reo de actos subversivos ${ }^{6}$. La desigualdad fue un imperativo incluso en las iniciativas de crear planteles educativos presentadas por algunos espíritus ilustrados que, buscando el adelanto del Reino, creyeron servir con ellas a todos los órdenes de la sociedad. Solo que allí no se olvidaban de precisar el requisito de que, "separados en clase, no se igualen, ni confundan, las condiciones" de los estudiantes?.

Esa desigualdad definitoria del vínculo social no fue aleatoria o voluble, no podía plasmarse de manera azarosa o desregulada, pudiendo así sugerir la volatilidad de los rangos y las virtudes que los acompañaban. La desigualdad, por el contrario, presentaba un carácter jerárquico que remitía a una bien trenzada serie de enlaces y órdenes sociales, siendo concebida como una condición ineludible para que los hombres de los distintos estados cooperaran al bien común. A los ojos de los neogranadinos, la desigualdad no aparecía como un atributo circunstancial sino que tendió a ser ontologizada, pese a la equivalencia de que es portador el cristianismo en cuanto reúne a los hombres en un mismo origen y en una común pertenencia a la iglesia. Porque este elemento de igualdad cristiana quedó enteramente dominado por el rol que se le asignó al pecado original en la definición de la naturaleza de los hombres y de sus comunidades políticas. Tras la expulsión del paraíso, se creyó en forma generalizada, la condición humana devino esencialmente frágil, vulnerable sobre todo a sus propias pasiones. Se podía admitir que la igualdad había existido antes de que los hombres se reunieran en sociedad, pero a partir de este momento se veía como una necesidad el establecimiento del orden jerárquico, único capaz de dar felicidad y armonía al mundo, el cual había recibido de Dios los criterios de su organización ${ }^{8}$.

6 José Manuel Pérez, Causas célebres a los precursores, T. I (Bogotá: Imprenta Nacional, 1939), $517-$ 519.

7 Guillermo Hernández, Documentos para la historia de la educación, T. VII (Bogotá: Patronato Colombiano de Artes y Ciencias, 1986), 27-28, 36. Véase también Felipe Salgar, Plan de creación de una escuela pública de primeras letras en Girón, 1789, en AGN, Colonia, Colegios, t. 2, f. 949-950.

8 Véase Manuel del Socorro Rodríguez, "Sigue el Apéndice sobre el Ensayo de la política", Papel Periódico de la Ciudad de Santafé de Bogotá, No. 246, 27 de mayo de 1796. 
La desigualdad jerárquica, pues, fue diversamente justificada como elemento valioso para el mantenimiento del orden y la concordia. La anarquía y la confusión, afirmaba un sujeto anónimo en 1800, "exigen necesariamente distinciones entre clases de hombres subordinados los unos a los otros". Pero el orden jerárquico no sería necesario solo en la tierra sino también en el cielo, donde Dios estableció el ejemplo primario de las jerarquías dando diversos grados de gloria a los “Ángeles y demás Espíritus bienaventurados" . Desde esa perspectiva, los hombres no podían serlo si no estaban inscritos en una relación de subordinación, pues un mundo en el que carecieran de sujeción sería un mundo de confusión y de horror, antagónico al paraíso y en cambio próximo al nullus ordo del infierno ${ }^{10}$. Después de la expulsión del paraíso a los hombres no les basta con su voluntad para obrar el bien: necesitan quien los guíe, quien los tutele, quien les ayude a sortear la amenaza del pecado y los meandros del desorden. Por eso el padre toma la tutela del hijo, el cura la de sus feligreses, los hacendados la de los indios, el esclavista la del esclavo, el marido la de la mujer, el profesor la del estudiante. Pero esta escala quedaría incompleta si por encima de todos esos vínculos de sujeción no fuera instalada una figura cimera que velara por la articulación y permanencia de ellos. El monarca habría sido el encargado por Dios de tal rol, y por ello lo invistió de los atributos necesarios. Según Manuel del Socorro Rodríguez, Dios se encarga de iluminar el entendimiento de quienes hace nacer para que gobiernen a los demás hombres. Incluso a los gobernantes de los pueblos bárbaros o gentiles Dios les transmite "ideas sublimes y virtuosas para que siempre triunfe la Justicia""11.

La justificación de la desigualdad como una herramienta del orden y del Estado no fue, por lo tanto, meramente instrumental, puesto que el buen orden hacía parte de los designios divinos. Entendida así, la desigualdad tendió a perder su origen humano y su historicidad. Y no pudo, tampoco,

9 Rafael Gómez Hoyos, "Un ensayo manuscrito de 1800”, Boletín de Historia y Antigüedades Vol. XLIX Nos. 567, 568, 569, (1962): 86.

10 Ubi nullus ordo es una expresión de Job harto conocida. La usa, entre muchos otros escritores, Bernard Lamy, en Entretenimiento sobre las ciencias, T. I (Madrid: Oficina de Benito García, 1800), 151.

11 Manuel del Socorro Rodríguez, "Sigue el rasgo apologético de la Legislación de Neméquene", Papel Periódico de la Ciudad de Santafé de Bogotá, No. 122, 27 de diciembre de 1793. 
concitar una animadversión significativa, ni siquiera entre quienes sufrían más a raíz de un principio que podía significar su deshumanización. Incluso un catedrático reivindicó en 1797 el "derecho de desigualdad", diciendo que estaba dictado por la ley natural prescrita por Dios ${ }^{12}$. Lo que sí concitó una animadversión intensa fue el proyecto de un "sistema de igualdad", que algunos publicistas vieron por entonces en marcha en Europa ${ }^{13}$. Aquel proyecto, propio de la filosofía de la Ilustración y la Revolución Francesa, les resultaba nefasto y quimérico, como lo eran también los derechos del hombre postulados desde tal perspectiva. Esos derechos del hombre, afirmó el cura Nicolás Moya, eran un plan para un pueblo que jamás había existido, porque ningún pueblo había abolido la subordinación ni había deseado las consecuencias de su implantación, consistentes en la extinción del legado del cristianismo. Aquellos derechos del hombre conllevarían, agregó, la entronización del asesinato, del fraude, del robo, del adulterio, entre otros males ${ }^{14}$.

El vínculo social, en segundo lugar, se le presentaba a los neogranadinos investido de una fuerte sacralidad, en el sentido que lo veían surgir de la potencia sagrada y ser salvaguardado por ella; un rasgo acentuado por el sacrificio que el propio Dios había hecho de su hijo para salvar a los hombres. Admiten que fue Dios quien puso a los hombres en contacto y los apremió a reunirse, pues la vocación de la sociabilidad está en la naturaleza humana, pero esta le habría sido conferida y dictada por la divinidad ${ }^{15}$. El vínculo social aparece dotado de carácter sagrado, además, porque habría sido la divinidad quien le dio a los hombres los cánones para la vida en común. Las leyes bajo las cuales deben vivir los hombres y deben regular sus intercambios, habrían sido directamente inspiradas por la "Providencia

12 Guillermo Hernández, Documentos para la historia de la educación en Colombia, T. V (Bogotá: Editorial Kelly, 1983), 362. Véase también "Continúa la exhortación de la patria”, Correo Curioso, Erudito Económico y Mercantil, Santafé de Bogotá, 3 de marzo de 1801.

13 "Prevención", Papel Periódico de la Ciudad de Santafé de Bogotá, No. 161, 10 de octubre de 1794; "Sigue la disertación", Papel Periódico de la Ciudad de Santafé de Bogotá, No. 163, 24 de octubre de 1794; Nicolás Moya, "Pieza remitida al autor del periódico", Papel Periódico de la Ciudad de Santafé de Bogotá, No. 239, 8 de abril de 1796.

2414 Nicolás Moya, "Sigue la disertación", Papel Periódico de la Ciudad de Santafé de Bogotá, No. 247, 10 de junio de 1796.

15 Circular del obispo de Trujillo a los curas de su jurisdicción, 1780, en "Preludios de la revolución de los comuneros en el Perú”, Revista del Archivo Nacional Año III Nos. 20/21 (1938): 4, 7-8. 
eterna”. Incluso las normas más triviales de la gastronomía, como aquella que permite saber si es lícito o no comer buñuelos y pescado en Navidad, encuentran su justificación en un canon divino y su discernimiento ortodoxo en la palabra de la Iglesia ${ }^{16}$. Por lo tanto, el vínculo social tiene por objeto permitir el cumplimiento del deber cristiano. El universo tiene un objetivo: el despliegue de un orden en el cual el género humano desarrolla una vida virtuosa, liberada de todo vicio, preludio de la definitiva felicidad de que gozarían los justos en el reino celestial. Tal horizonte no abre a los hombres la posibilidad de cualquier libertad, sino de una "cristiana libertad", una "libertad bien entendida", la única en la cual pueden alcanzar la excelsitud ${ }^{17}$.

La sacralidad del vínculo social comporta una serie de obligaciones, como servir a los semejantes con todas las facultades que el Ser supremo ha concedido. También exige amar a la sociedad de la cual se es miembro, pues como se arguye a mediados de la década de 1780 en un discurso, el derecho natural plantado por Dios en el corazón de los hombres los compele a servir a la Patria hasta el límite del sacrificio, "con amor, fidelidad, y celo", procurando que tenga la mayor gloria y las mayores ventajas posibles $^{18}$. La caridad cristiana, que impele a los hombres a amar al prójimo en cuanto es la imagen de Dios, los obliga también a amar al rey, no solo por ser la imagen de Dios sino también por ser un "Ministro suyo" destinado a su beneficio ${ }^{19}$. Poner en cuestión el carácter sagrado del vínculo social y de los mecanismos establecidos para su preservación, por lo tanto, era considerado un atentado de la mayor gravedad. Publicistas como Manuel

16 Consulta de Doña Ángela Isidra del Campo a Don Felipe de Vergara, y su respuesta sobre ¿si en Santafé de Bogotá será, o no lícito cenar la Noche buena, y cenar buñuelos y pescado? (Bogotá: Instituto Caro y Cuervo, 1993); Manuel del Socorro Rodríguez, sin título y “Continuación al No. 25”, Papel Periódico de la Ciudad de Santafé de Bogotá, Nos. 22, 26, 8 de julio y 5 de agosto de 1791.

17 José Celestino Mutis, 1801, en Apolinar Federico Gredilla, Biografía de José Celestino Mutis con la relación de viaje y estudios practicados en el Nuevo Reino de Granada (Madrid: Establecimiento Tipográfico de Fortanet, 1911), 50, 51, 58; Manuel del Socorro Rodríguez, "Sigue la materia del número anterior", Papel Periódico de la Ciudad de Santafé de Bogotá, No. 169, 5 de diciembre de 1794.

18 Discurso acerca del Derecho Público ofrecido en un acto literario llevado a cabo en el Colegio de San Bartolomé, en Archivo Histórico Javeriano (AHJ), Fondo Camilo Torres, carpeta 79, f. 5v.

19 "Edicto para manifestar al público el indulto general, concedido por nuestro Católico Monarca el Sr. D. Carlos III a todos los comprendidos en las revoluciones acaecidas en el año pasado de mil setecientos ochenta y uno" (Santafé de Bogotá: s.e., 1782), XIV-XV. 
del Socorro Rodríguez y Nicolás Moya, para quienes el estado primigenio de los hombres está determinado completamente por la voluntad divina, expresaron su repudio a la noción de estado de naturaleza propia de los filósofos ilustrados, por considerarla enteramente contraria al bien ordenado mundo legado por Dios a los hombres, y codificado y guardado por el catolicismo. En sus textos del Papel Periódico insisten en que el régimen establecido por los revolucionarios franceses no tiene otro objeto que "abolir y exterminar todo lo precioso y todo lo útil, para levantar sobre estas miserables ruinas el Trono de la tiranía"20. Por los mismos años, Joaquín Lorenzo Villanueva, autor de un catecismo de gran difusión, alertaba contra los perversos intentos de desacralizar el vínculo social adelantados por quienes admitían la "desatinada hipótesis" fundadora de la idea de pacto social, según la cual los hombres, a pesar del pecado original, habían conservado algo de su "libertad de insubordinación"21.

El vínculo social, en tercer lugar, está sujeto al imperativo de la incorporación, lo cual significa que los hombres no aparecen en el mundo como individuos sino como parte de un grupo, nacen integrados en el seno de una comunidad de sangre, una comunidad de fe y una comunidad política. No se concibe que nazcan sueltos o independientes, sino adheridos a una serie de pertenencias que le son marcadas de manera indeleble. Todas las cosas del mundo pregonan "enlace, armonía y sujeción”, tanto entre los miembros del cuerpo humano como del cuerpo político, y ese llamado debe ser acatado por todos los hombres, escribió Manuel del Socorro Rodríguez en $1791^{22}$. Parece incluso como si el desarrollo pleno de la vida debiera consistir en la asimilación de los hombres a los cuerpos que definen su existencia. Porque así como nacen integrados en unos cuerpos de referencia que les participan los atributos que los definen, los hombres deben permanecer por siempre integrados en ellos para poder realizar su condición humana y para ser ayudados a no desviarse de los objetivos comunes

20 "Fin de la disertación", Papel Periódico de la Ciudad de Santafé de Bogotá, No. 164, 31 de octubre de 1794.

2621 Joaquín Lorenzo Villanueva, Catecismo del estado según los principios de la religión (Madrid: Imprenta Real, 1793), X-XIII.

22 Manuel del Socorro Rodríguez, “Advertencia”, Papel Periódico de la Ciudad de Santafé de Bogotá No. 33, 23 de septiembre de 1791. 
a la especie. Para permanecer fieles a los designios de Dios. De ahí que las eventuales pretensiones de separarse de la familia, la Iglesia o la nación, sean delirantes y condenen de antemano a quien las sostiene a la pérdida de lo más valioso que tiene un ser humano, que es su honor, sus virtudes, su alma. Mostrar esa pretensión sería contrariar todos los cánones de la existencia social, separarse de la sociedad y vagar en las penumbras de un desierto metafísico. La articulación sin fisuras de los hombres en el cuerpo social, ese es el canon de normalidad, mientras que el deseo de independencia es considerada una absoluta anomalía, llegando a ser asociada por algún cura a los designios de Satanás ${ }^{23}$.

La pretensión que algunos individuos supuestamente alimentaron en la década de 1790, de "singularizarse" con respecto a los demás fue por lo tanto censurada, viéndola como una excentricidad dañina ${ }^{24}$. El deseo de singularidad fue equiparado al deseo de independencia, como lo denunciaron reiteradamente en el Papel Periódico cuando criticaron a ciertos hombres de letras o a algunos ambiciosos de brillo intelectual. Esos "Genios sublimes", afirmaron, presumen con argumentos peregrinos "defender la causa de la Humanidad" invocando los "privilegios con que el derecho natural ha enriquecido al hombre". Pero lo que esos "reformadores del Universo" en realidad logran de esta manera es contrariar la naturaleza, la religión, la filosofía, las leyes, y dejar las sociedades sin soberanos, sin vasallos y sin Dios. Lo único que dejan en pie es el fanatismo, la anarquía y la revolución ${ }^{25}$.

"Fingid un hombre aislado sin conexiones, sin dependencia, sin trato, sin

23 Antonio Julián, Monarquía del diablo en la gentilidad del Nuevo Mundo americano (Bogotá: Instituto Caro y Cuervo, 1994), 183; Nicolás Moya, "Pieza remitida al autor del periódico", Papel Periódico de la Ciudad de Santafé de Bogotá No. 239, 8 de abril de 1796; Memorial de Salvador Plata, 1782c, en Manuel Lucena, El memorial de Don Salvador Plata (Bogotá: Instituto Colombiano de Cultura Hispánica, 1982), 94-95, 103, 200.

24 Representación de Manuel del Socorro Rodríguez al Secretario de Gracia y Justicia, abril de 1793, en Archivo General de Indias (AGI), Estado, 53, No. 84-H, s.f.; Joaquín Lorenzo Villanueva, Catecismo del estado, 85; Manuel del Socorro Rodríguez, "Plan elemental del buen gusto en todo género de materias”, 1800c, Biblioteca Nacional, RM 435, pza. 11, f. 93r.

25 "Retrato histórico de Luis XVI. Sobre el trono", Papel Periódico de la Ciudad de Santafé de Bogotá, No. 138, 18 de abril de 1794; "Carta pastoral del Ilmo. y Rmo. Señor D. Fr. Adeodato Turchi del orden de capuchinos (Valencia: impreso por Martín Antonio Peris, 1790), 6-7. 
auxilios, sin objetos, sin fines, y concluiréis la verdad, de que sería el animal más desgraciado e infeliz", escribieron en un periódico de la capital virrei$\mathrm{nal}^{26}$. Pretender la independencia sería querer persistir en la falta primigenia del hombre, pues el pecado de Adán consistió justamente en su amor a la independencia ${ }^{27}$. Tal vez por narrar la vida de un hombre solitario, un hombre en una situación tan ajena a las disposiciones de Dios, el libro de Daniel Defoe que relata las aventuras de Robinson Crusoe fue considerado peligroso y por lo tanto prohibido en toda la monarquía española ${ }^{28}$. De ahí que si algunos publicistas llegan a aceptar la existencia de unos "derechos de los hombres", estos sean esencialmente distintos a los que asocian a la Revolución Francesa. En primer lugar porque la noción de derechos no les habla de una potestad de los individuos para reclamar algo que les pertenezca por su mera condición humana. En segundo lugar, porque admiten no los derechos de un tipo de hombre independiente sino de hombres reunidos, juntados por unos deberes y una autoridad irrecusables ${ }^{29}$.

El vínculo social, en cuarto lugar, antecede al individuo: el hombre no tiene opción de escoger su subordinación a las personas, las normas y las instituciones que encarnan el canon de una vida buena. Los hombres entran al mundo con un tipo de subordinación que no nace de un convenio o contrato que puedan deshacer o alterar según su conveniencia, puesto que la subordinación no brota de un acto voluntario acordado en el ámbito humano. Los hombres nacen obligados a sujetarse a unas normas de derecho natural y divino que les prescriben cómo obrar consigo mismo, con sus semejantes, con la autoridad humana y divina. Y si el vínculo social no nace de una escogencia, resulta repudiable el pensamiento que acepta que los hombres deciden de qué manera viven, con qué reglas, con qué autoridades.

26 "Continúa la exhortación de la patria", Correo Curioso, Erudito Económico y Mercantil, No. 3, Santafé de Bogotá, 3 de marzo de 1801.

27 Joaquín Lorenzo Villanueva, Catecismo del estado, XII, 22.

28 Índice último de los libros prohibidos y mandados expurgar: para todos los reynos y señoríos del Católico rey de las Españas (Madrid: Imprenta de Don Antonio de Sancha, 1790), 233. La existencia de un hombre solitario es admitida apenas como posibilidad de una época imaginaria, la cual había evocado en algunos textos el portugués Teodoro de Almeyda (Manuel del Socorro Rodríguez, "Sigue el apéndice sobre el Ensayo de la política", Papel Periódico de la Ciudad de Santafé de Bogotá, No. 247, 10 de junio de 1796).

29 Manuel del Socorro Rodríguez, "El reino feliz fundado sobre los principios de la verdadera filosofía”, 1794, AGI, Estado, 53, No. 84, f. 15. 
Antes del pecado original, escribió hacia 1789 el cura Joaquín de Finestrad, los hombres estuvieron cobijados por la gracia de nacer y permanecer libres e iguales, redimidos, además, de todas las pasiones que les provocan la infelicidad. A raíz de la desgraciada acción del padre Adán, los hombres se corrompieron, olvidaron el interés común, vieron multiplicarse sus pasiones, sus intereses y sus guerras, situación que los llevó a querer congregarse en sociedad y hacer que la seguridad dependiera de sus enlaces mutuos. Y efectivamente, los hombres instituyeron la comunidad política y con ella la legislación, y así restablecieron sus derechos naturales y el mundo se tornó feliz y armonioso, afirma Finestrad. En este punto habría comenzado la verdadera historia de la humanidad, pues "sucedió la subordinación a la independencia, el orden a la confusión, a las violencias la justicia y la pública tranquilidad a las inquietudes" ${ }^{30}$. Pero el tipo de vínculo social que habrían establecido los hombres en aquel momento en que trataban de superar el caos post-edénico, no habría sido el fruto de una escogencia que les hubiera permitido poner en marcha cualquier tipo de experiencia humana. En aquel instante primigenio en que reformaban el vínculo social buscando instaurar las condiciones para el desarrollo de una vida virtuosa, los hombres optaron por la única forma buena de orden: aquel orden hecho a la imagen de un solo hombre hipereminente, dotado de una autoridad fundada y ratificada por Dios. Esa decisión, pues, no nació de una voluntad que pudiera considerarse propiamente libre, pues anhelando coincidir con los designios divinos, los hombres estaban obligados de antemano a seguir unos cánones de singular fuerza ${ }^{31}$. El orden social inspirado en la figura del príncipe católico era por lo tanto un destino y no una escogencia. Desde el punto de vista de los publicistas del poder monárquico absoluto, no es que el régimen monárquico logre hacer retornar al hombre al estado bienaventurado de que había gozado en el paraíso, pero sí cumple la función de aproximarlo en cuanto limita la acción disolvente de los vicios que le impiden recibir la gracia divina. La monarquía se erige en garante de que el hombre pueda acceder a la ciudad de Dios, pues se ocupa de no dejarlo pecar y da toda la amplitud posible a la verdad católica para que tome posesión de criaturas que de otro modo se despeñarían en el pecado.

30 Joaquín de Finestrad, El vasallo instruido (Bogotá: Universidad Nacional, 2000), 331-332, 380.

31 Joaquín de Finestrad, El vasallo instruido, 201, 307, 308, 312-314. 
Desde la perspectiva de los neogranadinos, los hombres nacen con compromisos irrenunciables, y por eso Finestrad alude en un aparte a las "obligaciones que la humanidad manda, que el Cristianismo establece y que la Majestad ordena"32. Desde esta perspectiva, es inconcebible la existencia de un estado primigenio de naturaleza donde los hombres puedan estar reunidos para trazarse cualquier objetivo como individuos y como sociedad. Es inadmisible la existencia de unos "derechos del hombre" que los hombres mismos definan. En la hipótesis de que sean admitidos esos derechos, ellos son algo ya dado y están enmarcados por los designios de Dios. El objeto del vínculo social escapa a los hombres, y sus derechos tienen por objeto no la realización de su libertad sino la realización de la verdad católica. Un defensor de la soberanía absoluta del príncipe, como lo fue Manuel del Socorro Rodríguez, no dejó de reconocer que los “derechos del hombre" eran algo efectivamente precioso, pero advirtió que había dos maneras antitéticas de concebirlos. Una, quimérica y abominable inspirada en "los fanáticos filósofos de nuestros días", y otra, nacida de la razón y la justicia propias del orden monárquico. La primera es la versión revolucionaria de los derechos del hombre en la que estos no son sino un artificio para engañar a la multitud y hacerla adherir a nefastos propósitos. Los derechos del hombre, desde ese punto de vista, están fundados en la pretensión de que "todo hombre tenga amplia y entera libertad de hacer, y deshacer por sí mismo cuanto se le antoje en orden a la moral, a la política, y a la religión". Propósitos estos que son delirantes y que asocia a individuos licenciosos y brutales. Rodríguez postula otra manera, esa sí recta, de concebir los derechos del hombre, los cuales vienen a consistir en la búsqueda del bien común de la sociedad, en el reconocimiento de la virtud y en el castigo del vicio, objetos que no pueden ser alcanzados sino mediante un poder soberano tocado por la gracia de Dios. Los "verdaderos derechos del hombre", dice, son los bienes más preciados por la especie humana, que eventualmente pueden estar amenazados y que solo el buen orden de la sociedad y una autoridad eminente derivada de Dios están en disposición de defender ${ }^{33}$. sin título, Papel Periódico de la Ciudad de Santafé de Bogotá, No. 22, 8 de julio de 1791.

33 Manuel del Socorro Rodríguez, "La república feliz, fundada sobre los principios de la verdadera filosofía. Discurso dirigido a todos los hijos de la Ciudad de Santafé, por uno de sus más ingenuos y 
Finalmente, vale la pena subrayar cómo desde el punto de vista de la experiencia neogranadina, el rey fue la figura sintetizadora y garante del vínculo social $^{34}$. Posibilitó la limitación de las tensiones, la domesticación de las pasiones, la represión de la insidiosa maldad, haciendo que los súbditos permanecieran en la quietud y la confianza. Pero fue concebido sobre todo como un instrumento para que los hombres y la sociedad en su conjunto cumplieran el designio que estaba inscrito en la providencia divina. El soberano, dice el cura Nicolás Moya en 1795, “es como la Alma de este gran Cuerpo civil; que los miembros políticos exponen su vida por guardarle, porque él a todos guarda; y que si faltase este objeto respetable y consolador, esta cabeza augusta, este Padre común, este centro de unión y de armonía, todo el cuerpo nacional palpitaría agonizante en la revolución y trastorno" 35 . Dado que el rey fue símbolo y guardián del vínculo social, atentar contra su autoridad hubiera sido atentar contra la armonía y la existencia misma de la sociedad. Por esto un funcionario real despreció en 1781 la enorme revuelta de los comuneros argumentando que al hacer esto esa "vil plebe" se había separado del rey, había atropellado y usurpado la autoridad pública, y había "roto los vínculos de la sociedad civil"36.

\section{RUPTURA Y RECONSTRUCCIÓN REVOLUCIONARIA DEL VÍNCULO SOCIAL}

Muchos de quienes vivieron la Revolución Neogranadina eran conscientes de que el antiguo vínculo social había quedado disuelto y había comenzado a tejerse otro vínculo de naturaleza distinta. Dicha percepción fue expresada de diversas maneras en todo el reino, pero llaman la atención algunas alusiones a dicha situación como una anarquía primigenia. José María Gutiérrez, por ejemplo, manifestó en agosto de 1810 en Mompós

amantes Compatriotas”, 1794, en AHJ, Fondo Camilo Torres, carpeta 89, f. 2-19. La Real Audiencia aludió en 1795 a los "verdaderos derechos del hombre", los cuales ven supeditados a unas "sagradas obligaciones de los hombres para con la Religión, con el Rey, con la Patria, con la Sociedad” (José Manuel Pérez, Causas célebres, 88-89).

34 Quizá hubo grandes semejanzas en la concepción del rey en la sociedad neogranadina y en la sociedad metropolitana. Esto lo sugiere la lectura del libro de María Pilar Monteagudo, La Monarquía ideal. Imágenes de la realeza en la Valencia moderna (Valencia: Universitat de València, 1995).

35 Nicolás Moya, "Sigue la materia del nº anterior", Papel Periódico de la Ciudad de Santafé de Bogotá, No. 190, 1 de mayo de 1795.

36 Juan Friede, Rebelión comunera de 1781. Documentos, T. II (Bogotá: Instituto Colombiano de Cultura, 1982), 893. 
que la redención del reino, operada a partir del 20 de julio de este año, había podido verificarse porque ella había radicado en el principio de la "anarquía", es decir, en la "justa reasumisión que una sociedad hace de sus derechos que otra sociedad le tenía usurpados, y a quien oprimía en nombre de la Divinidad”. El joven cucuteño comparó esa anarquía con la "santa igualdad", la cual constituía el fundamento de la felicidad de los pueblos. Por otro lado, un año después el gobierno de la Provincia de Antioquia utilizó la expresión "perfecta anarquía” para significar que los "vínculos sociales" habían quedado rotos luego que el 20 de julio en la capital virreinal los "sátrapas" habían sido despojados del "trono de la tiranía"37. Esa anarquía que revelaba la completa ruina de los lazos sociales y abría la posibilidad a la felicidad podía, sin embargo, generar simplemente el caos. Lo expresó gráficamente un periódico a mediados de 1813 cuando alertó que sin la virtud, la instrucción y el patriotismo, la tan exaltada búsqueda de la libertad no llegaría sino a un "grosero y brutal libertinaje, digno de compararse con aquel horrible nullus ordo del infierno" 38 .

El temor implícito en la metáfora del caos infernal no se tomó, empero, el espíritu de los revolucionarios, en quienes la refundación a que había quedado abocada la sociedad produjo más bien grandes esperanzas. Tales ilusiones no fueron ajenas a la relación tan estrecha que se estableció entre esa desarticulación de la sociedad y la rutinización del concepto de "estado natural" 39 , con toda la carga de optimismo idílico que portaba la creencia de que con la Revolución, la sociedad neogranadina había entrado en un estado similar al que habían gozado en su momento los hombres primigenios de la metáfora roussoniana, lo cual permitía un reinicio en la dirección ideal, despojados ahora los neogranadinos de todos los lastres y

37 Manuel Ezequiel Corrales, Documentos para la historia de la Provincia de Cartagena de Indias, hoy Estado Soberano de Bolívar en la Unión Colombiana, T. I (Bogotá: Imprenta de Medardo Rivas, 1883), 192; Daniel Gutiérrez, Las asambleas constituyentes de la independencia (Bogotá: Corte Constitucional/Universidad Externado, 2010), 212.

38 "Rasgo sobre la libertad”, Gazeta Ministerial de Cundinamarca, No. 107, Santafé de Bogotá 22 de abril de 1813 .

3239 Véase, por ejemplo, proceso contra Ignacio Vargas, 1810, en AGN, Sección Archivo Anexo, Fondo Justicia, t. 8, f. 664r; Oficio de la Junta de Santafé, 1810, en Archivo Histórico José Manuel Restrepo (AHJMR), fondo I, Vol. 4, f. 129; “Siguen los preliminares”, El Republicano, No. 23, Tunja, 20 de septiembre de 1815. 
habilitados para acometer cualquier proyecto de transformación. La Revolución Neogranadina también generó grandes frustraciones y temores, pero con ella emergió un nuevo tipo de vínculo social, algunos de cuyos atributos son su fundamentación en el principio de la igualdad, su carácter mundano, la necesidad que tiene del consentimiento, así como su obligatoriedad. A grandes rasgos describiré esos atributos.

El vínculo social, en primer lugar, pasó a estar definido por el horizonte de la igualdad, habiéndose forjado en la Nueva Granada una serie de discursos, de sentimientos, de actitudes que reclamaron la equivalencia entre los hombres como medida de lo justo y lo deseable. La igualdad tiene su síntesis en el ciudadano, figura que ayuda a hacer visible a un soberano informe, a un pueblo príncipe compuesto de átomos teóricamente equivalentes. El ideal de igualdad, declarado constitucionalmente e invocado copiosamente por los novadores neogranadinos, fluyó hacia los diversos órdenes de la sociedad. En la parroquia del Cocuy, en la provincia de Tunja, los indios, según denunció en junio de 1811 el cura de ese pueblo, dieron una "perversa inteligencia" a un bando publicado de orden de la antigua capital virreinal sobre "igualación con los Blancos" ${ }^{40}$. En Cartagena, la igualdad a que innumerables veces fue convidado el bajo pueblo de todos los colores dio una vivacidad especial a las luchas políticas, de manera que un cura desterrado pudo deplorar que "una chusma de negros, zambos y mulatos" hubiera participado en la instalación de la junta de gobierno ${ }^{41}$. Desde la Parroquia de Llanogrande (provincia de Popayán) un grupo importante de vecinos se quejó en junio de 1812 del exceso de impuestos que seguían pesando sobre los "pobres" y dijeron que, mientras en la provincia no hubiera una ley general que, "nos ponga a nivel y extirpe distinciones no puede haber felicidad" ". El ideal igualitario abrió las puertas en el ejército aún a "zapateros, cocheros y porqueros", para congoja de un cura lealista, mientras que a los cómicos, tanto como a los demás menestrales, se les

40 AGN, Sección Archivo Anexo, Fondo Historia, t. 12, f. 542.

41 Informe de fray Juan Antonio Díaz Merino dirigido a las Cortes sobre la situación política de Cartagena, agosto de 1811, en Jairo Gutiérrez y Armando Martínez, La visión del Nuevo Reino de Granada en las Cortes de Cádiz (1810-1813) (Bogotá: Academia Colombiana de Historia/UIS, 2008), 173-174.

42 Archivo Histórico Municipal de Cali, Fondo Cabildo, t. 38, f. 67r. 
debieron reconocer los "derechos del hombre" consignados en la Constitución, como lo hizo en 1813 el presidente de Cundinamarca, Antonio $\mathrm{Nariño}^{43}$. Un publicista incluso llegó a ver en el "celo indiscreto de igualdad" que abundaba, un obstáculo a la consolidación de la revolución ${ }^{44}$.

El principio de la igualdad que vino a impregnar el vínculo social fue plasmado con mayor evidencia en el orden jurídico, de manera que las diversas constituciones provinciales acordaron a los ciudadanos una igualdad concebida como un derecho natural. No es que los hombres queden ahora igualados en sus cualidades físicas y espirituales sino que, siendo considerados iguales en naturaleza, deben serlo también delante de la ley. Los redactores de las bases fundamentales de la Constitución del Socorro, por ejemplo, alegaron que su deposición del corregidor virreinal a mediados de 1810 había consistido en la ruptura del "vínculo social" y en la devolución al pueblo de sus "derechos naturales, e imprescriptibles de libertad, igualdad, seguridad y propiedad" ${ }^{45}$. El Síndico Procurador de Cartagena manifestó que Dios había dado a todos los hombres una "igualdad de derechos" a la cual no se podía renunciar sino en la precisa parte que la filosofía indicaba como necesaria para la conservación de la propia existen$\mathrm{cia}^{46}$. De esta igualdad ante la ley se desprendía a su vez el precepto según el cual todos debían ser premiados y castigados con la misma medida, debiendo ser abolidas las distinciones por razones diferentes a los servicios a la república ${ }^{47}$. $\mathrm{Al}$ afirmar que ya no era con fundamento en el nacimiento o la posición social sino en el mérito, la virtud y los servicios prestados a la república que esta distinguiría a los ciudadanos, nacía un nuevo criterio para las distinciones legítimas en el orden político, el cual repercutiría hondamente en la vida social.

43 José Antonio de Torres y Peña, "Memorias sobre la revolución y sucesos de Santafé de Bogotá", en Memorias del Presbítero José Antonio de Torres y Peña (Bogotá: Editorial Kelly, 1960), 122; Oswaldo Díaz, Copiador de órdenes del Regimiento de Milicias de Infantería de Santafé (1810-1814), (Bogotá: Fuerzas Armadas, 1963), 231-232.

44 "Un extranjero domiciliado en la N G a los Colegios Electorales y Constituyentes sobre la duración de los empleos", Argos de la Nueva Granada, No. 73, Santafé de Bogotá, 14 de mayo de 1815.

45 Bases fundamentales de la Constitución del Socorro, agosto 1810, en AHJMR, fondo I, Vol. 4, f. 66r.

46 Relación de las Providencias que se han dado por el MIC de Cartagena de Indias (Cartagena: Impren-

34 ta del Real Consulado, 1810), 26.

47 Constitución de la República de Tunja (Santafé de Bogotá: Imprenta de D. Bruno Espinosa, 1811), 5, 48-49; "Continúa la prevención contra los esfuerzos de los Realistas", Gazeta Ministerial de Cundinamarca, No. 188, Santafé de Bogotá, 1 de septiembre de 1814. 
El acontecimiento revolucionario convirtió en antinatural e inmoral el principio jerárquico que había impregnado la antigua sociedad. De ahí que, si bien la Revolución Neogranadina avanzó apenas modestamente en derribar las enormes asimetrías de estatus y de fortuna así como las formas corporativas de organización de la sociedad, a partir de entonces las expresiones más sobresalientes de la desigualdad vieron comprometido su futuro. Con la Revolución vemos emerger demandas de derechos y libertades, vemos intervenir a múltiples actores en la escena pública, vemos surgir algunos mecanismos de ascenso social y aligerarse ciertas constricciones sociales, particularmente en los matrimonios. Siendo todo esto significativo, la fuerza del principio de igualdad radicó ante todo en que quedó instalado como un horizonte, como un deber ser. Como una promesa a cuya luz podían ser juzgados todos los actos y las relaciones sociales.

El vínculo social, en segundo lugar, aparece ahora investido fuertemente de mundanidad, en contraste con el orden monárquico, donde había aparecido como si su establecimiento precediera a la intervención humana. La noción de pacto, que nace y toma enorme fuerza con la Revolución Neogranadina, nos permite acercarnos a esa mundanidad que ahora asume el vínculo social, pues pasa a creerse que es solo a partir del pacto que un conjunto de hombres comienza a tener una existencia propiamente en común. Una frase de la Junta de Santafé permite aprehender el giro que entraña tal adjudicación de un origen mundano al vínculo social. En una proclama de 1810 ella ubica el punto de origen de las sociedades humanas en el "pacto de amistad entre los primeros padres", el cual habría sido celebrado "un instante después de la creación”. La sutileza de esta expresión, "un instante después de la creación", insinúa que no ha sido en los terrenos de la divinidad sino en el campo prosaico de los hombres, que ha sido anudado el lazo entre los hombres ${ }^{48}$. El vínculo social es mundano por su origen, pero también por su fin: el objeto que reúne a los hombres en un cuerpo político es ante todo poder gozar y preservar sus derechos naturales: libertad, propiedad, seguridad. También son objeto de esa reunión

48 Proclama de la Junta de Santafé, en AHJMR, fondo I, Vol. 4, f. 74r. En enero de 1811 la Junta de Pore juró adhesión a la Junta de Tunja "ante el Supremo Ser y los hombres" (AHJMR, fondo I, Vol. 4, f. 442r). 
la prosperidad y la felicidad, como lo afirman a lo largo de la Revolución muchas voces ${ }^{49}$.

A la sociedad, pues, se le asignó por meta primordial el mayor desarrollo de los intereses humanos, la mejor garantía de alguna forma de bienestar mundano. Así, tanto los derechos del hombre como el vínculo social a los cuales sirven de fundamento, son definidos como sagrados, como se repetía por doquier. Un anónimo ciudadano de Popayán escribió que los "vínculos que mantienen la integridad de un cuerpo político, son sagrados", y "la parte que rompe su unidad, por sí sola, viola el derecho de las gentes que reprueba toda división tumultuaria, y caprichosa sin el voto general" "50. Mientras que el Cabildo de Santafé de Antioquia expresó que "las condiciones del pacto social deben ser sagradas en toda su extensión", y la Constitución de esa provincia sentenció que el "Contrato Social es el más sagrado de todos los contratos, y obliga mutuamente a los súbditos y superiores, no solo delante de los hombres sino también delante de Dios" ${ }^{\prime 51}$.

Afirmar que el vínculo social es sagrado tiene, empero, un sentido enteramente distinto al que había tenido en el orden monárquico. Es sagrado porque es voluntad divina que los hombres vivan en sociedad, porque los objetos de la comunidad política y el vínculo social mismo deben gozar de un respeto superlativo, porque quienes atentan contra la armonía social tienen en este mundo y el otro graves responsabilidades ${ }^{52}$. Pero el califica-

49 Véase: “Contestación de los editores a la carta tercera del Sr. P.”, El Argos Americano, No. 37, Cartagena, 10 de junio de 1811; "Oficio circular de los Representantes nombrados para el Congreso general por las provincias libres del Reino dirigido a sus respectivos gobiernos", El Argos Americano, No. 54, Cartagena, 30 de septiembre de 1811; “Cartagena de Indias”, El Español, No. XXVI, Londres, 30 de junio de 1812, 145; Constitución del Estado de Cartagena de Indias sancionada en 14 de junio del año de 1812 (Cartagena: Imprenta del Ciudadano Diego Espinosa, 1812), 5; "Continuación del núm. 6 del Observador Colombiano”, Gazeta Ministerial de Cundinamarca, No. 153, Santafé de Bogotá, 20 de enero de 1814.

50 Carta de un payanés anónimo, septiembre de 1810, en AGI, Estado, 57, No. 29, 1, sin foliación.

51 Cabildo de Antioquia, diciembre de 1814, en AHJMR, fondo I, Vol. 7, f. 468v-469r; Constitución provisional de Antioquia, revisada en Convención de 1815 (Medellín: Imprenta del Gobierno, 1815), 8.

3652 Miguel de Pombo, Constitución de los Estados Unidos de América (Santafé de Bogotá: Imprenta Patriótica, 1811), XLI; Francisco Florido, Sermón que en la fiesta de Santa Librada hecha en obsequio del Excmo. Señor Presidente Don Antonio Nariño por el Ilustre Cabildo de la Villa de Bogotá, pronunció el P. L. Francisco Florido de la Orden de San Francisco (Santafé de Bogotá: Imprenta de D. 
tivo de sagrado que recibe el vínculo social no comporta la idea de que el poder, y los lazos que de él se derivan, han sido algo instituido por Dios y por lo tanto irrecusables. Mientras que en la sociedad monárquica, tal como lo vemos enunciado en las décadas anteriores a la Revolución, Dios le entrega al soberano las riendas y las claves del gobierno, ahora nadie niega que Dios sea creador de todo, pero el impulso para que un grupo de seres humanos se reúna en una comunidad política proviene de esos mismos hombres: a estos no les es dado de antemano el conglomerado en el cual deben vivir, ellos mismos lo instituyen. En el régimen democrático que emerge, la sociedad se autoasigna como realización tanto los derechos del hombre como la felicidad y la prosperidad, objetivos compatibles con las verdades evangélicas, pero que no necesitan de ellas para existir y permanecer vigentes. La religión, entonces, puede ser ensalzada porque permite realizar la libertad, como lo consigna la Constitución de Cartagena: "No pudiendo haber felicidad sin libertad civil, ni libertad sin moralidad, ni moralidad sin Religión, el Gobierno ha de mirar la Religión como el vínculo más fuerte de la sociedad, su interés más precioso y la primera ley del Estado" 53 . Se puede incluso creer que Dios otorga al hombre unos derechos y libertades, pero estos no quedan sujetos a una delimitación o a una garantía que no sean de este mundo. La posición de la religión respecto al poder sufre, por lo tanto, un cambio esencial: mientras en la sociedad monárquica la verdad católica es fin y garante del ordenamiento social, a partir del acontecimiento revolucionario la verdad católica deviene un medio, un instrumento de la cohesión social, pero la sociedad no se autoasigna como realización la verdad católica.

La Iglesia, entonces, seguirá siendo defendida intensamente por cuanto constituye una especie de cemento del lazo social, un factor importantísimo de cohesión, aunque ella ahora no sea la ultima ratio del vínculo social. A finales de 1810 la Junta de Santafé reconoció que nada es más necesario para la "feliz organización" del cuerpo social, que el ejercicio de la autoridad religiosa por parte de los jefes católicos, pero expresiones como estas

Bruno Espinosa, 1812), 12; Actas del Serenísimo Colegio Constituyente y Electoral de la Provincia de Cundinamarca. Congregado en su capital la ciudad de Santafé de Bogotá para formar y establecer su Constitución (Santafé de Bogotá: Imprenta Real, 1811), 51-52. 
no indican que la Iglesia deba seguir siendo la depositaria de una verdad que sea la meta implícita del cuerpo político, sino más bien que la Iglesia ha devenido una herramienta del orden social. Podemos ver esta desvalorización de la Iglesia en la manera como el Poder Ejecutivo de Cundinamarca rechaza las expresiones contra la religión, aparentemente profusas, que aparecieron a finales de 1813. No solo porque defiende la religión utilizando referencias de autores latinos de la Antigüedad sino ante todo porque su justificación es de orden práctico: aquella sirve de medio para dar armonía al cuerpo político, puesto que es "un freno que contiene al pueblo y que modera la autoridad de las potestades" 54 . No se trata en absoluto, como quieren algunos curas lealistas acorralados por los revolucionarios, de una defensa de la religión católica porque su verdad constituya el objetivo de la república así como de cualquier comunidad política ${ }^{55}$.

La impronta del ideal mundano sobre el vínculo social constituye una humanización del mundo, en el sentido que la divinidad tiende a ser retirada de la escena para dejar en primer plano a los hombres, con sus ideales, sus necesidades, sus defectos. La Revolución Neogranadina llevó a la sociedad a organizarse bajo el supuesto de que ella estaba originada en la acción de los hombres y destinada ante todo a servir a su perfeccionamiento.

El vínculo social vino a ser, en tercer lugar, expreso y consentido, no algo que los sujetos han adquirido de antemano, algo que al llegar a la sociedad el individuo trae y lo obliga sin que él intervenga de alguna manera en su creación y en el establecimiento de las normas que lo preserven. En este sentido un escritor anónimo advirtió en 1810 a los novadores santafereños que sin el consentimiento de los "hombres libres" de América no podía trastornarse el "orden social” que los ligaba entre sí, ni formarse leyes distintas de las que los habían regido hasta el momento ${ }^{56}$. En la medida

54 "La Suprema Junta en su Cuerpo Ejecutivo", Diario Político de Santafé de Bogotá, No. 25, Santafé de Bogotá, 20 de noviembre de 1810; "Acuerdo del Supremo Poder Ejecutivo", Gazeta Ministerial de Cundinamarca, No. 141, Santafé de Bogotá, 11 de noviembre de 1813.

55 José Antonio Torres y Peña, Viva Jesús. La voz de la religión, contra el papel sacrílego, que con agravio de lo más sagrado se titula falsamente: la voz de la verdad (Santafé de Bogotá: Imprenta de Jesús, 1813), 6-9.

56 El Buen Patriota, "Observaciones que dirige un amigo a otro que le pregunta sobre la actual situación del Reyno en agosto de 1810”, Biblioteca Nacional, Fondo Pineda 184, pza. 8. 
que el vínculo social no está determinado de antemano en el tiempo, la eventualidad de ventajas o penas que deriven de los ancestros o reviertan sobre los descendientes, resulta algo inaceptable. Las distinciones que un hombre puede recibir en la república, como fruto de sus virtudes, su talento o sus servicios, no puede transmitirlas, como no puede ser tolerada "la idea de un hombre que nazca Rey, Magistrado, Legislador, o Juez", por ser "absurda y contraria a la naturaleza", como lo establece la Constitución de Tunja y lo repiten otras constituciones. Al igual que los premios, el castigo de las faltas debe separar totalmente al infractor respecto a su familia, coincidiendo todos los legisladores en que "ninguna pena de cualquier clase que sea, será trascendental a los descendientes, ni a las familias del que las sufra, debiendo tener todo su efecto en solo el delincuente", como lo consignó el proyecto de Constitución para Popayán ${ }^{57}$.

El vínculo social deja, pues, de basarse en el imperativo de los ancestros y de la tradición. El origen del cuerpo político en medio del cual se desarrolla dicho vínculo es adjudicado ahora a una "voluntaria asociación de los individuos, por la cual todo el pueblo estipula con cada ciudadano y ellos con todo el pueblo que todos serán gobernados por ciertas leyes para el bien común”, como lo expresó la Constitución de Cartagena, inspirada en la de Massachusetts ${ }^{58}$. De esto se deriva que el vínculo social aparezca ahora revestido de una notoria artificialidad, la cual proviene de la artificialidad del nuevo soberano. Mientras que el príncipe soberano pudo con bastante éxito aparecer como una criatura de Dios y como una creación natural, el soberano de la democracia no puede, tampoco lo busca, esconder nada de la artificialidad de su origen, de forma tal que fácilmente llega a ser tenido por una creación de la mente de unos filósofos ilusos.

Al carácter voluntario de que es investido el vínculo social se le añade la exigencia de que sea adoptado de manera expresa y personal. Así, un funcionario judicial da por sentado que "en el primer instante de la formación de una nueva sociedad, bajo cualquiera forma, todos los individuos están

57 Constitución de la República de Tunja, 5; “Constitución de la Provincia de Popayán”, Boletín Histórico del Valle, Nos. 49-53 (1938): 50.

58 Constitución del Estado de Cartagena, 3. En igual sentido se pronuncia el Reglamento para el gobierno provisorio de la Provincia de Pamplona (Tunja: Imprenta del Estado, 1815), 3. 
en libertad para hacerse, o no miembros de ella"59. Las muchas peticiones de pasaporte por parte de los descontentos con la nueva comunidad política muestran cómo arraiga la idea de que la pertenencia a una comunidad política es voluntaria, sin que pueda eludirse la toma de posición, pues o se pertenece a ella o se le abandona. Al no aceptarse que el vínculo social es algo dado, pasó a rechazarse la hipótesis de un poder hereditario ${ }^{60}$. Así, tras las juntas de 1810 vemos generalizarse la idea según la cual el nuevo gobierno y las nuevas instituciones, incluida la Constitución que casi todas las provincias quisieron darse, nacían exclusivamente de la voluntad y el consentimiento de los hombres de una determinada demarcación. Igualmente se tornó en lugar común la adjudicación al pueblo del pleno derecho de modificar o instaurar un nuevo régimen político cuando el existente resultara incapaz de asegurar la existencia del cuerpo político y de garantizar a los individuos que lo componen sus derechos. En la Constitución de Neiva (1815) acordaron que siendo el fin de cualquier gobierno el bien común así como la protección y seguridad del pueblo, este tenía un "incontestable, inalienable e imprescriptible derecho para establecer su Gobierno, para reformarle, alterarle o absolutamente variarle”, cuando lo exigieran los fines de su asociación. De manera, que en un régimen democrático como el que se dieron casi todas las provincias neogranadinas, la cesión del pueblo de su potestad de instituir la autoridad era considerada una actitud "incompatible con la naturaleza del cuerpo social, y contraria al fin de la asociación”, como lo dictaminó la Sala de Gobierno y Hacienda de Cundinamarca ${ }^{61}$.

Si la autoridad ahora es instituida por medio de un gesto voluntario de los

59 Ramón de la Infiesta Valdés, "Ramón de Infiesta habla", Biblioteca Nacional, VFDU1-445, pza. 947.

60 En este punto los revolucionarios sin duda encontraron inspiración en Thomas Paine, quien se ocupa detallada y repetidamente de recusar a los gobiernos "por sucesión hereditaria". Estos se oponen, para él, a los gobiernos “por elección y representación”, que entrañan todas las virtudes. Ver Thomas Paine, La Independencia de la Costa Firme justificada por Thomas Paine treinta años ha (Filadelfia: Imprenta de T. y J. Palmer, 1811), 18-66.

61 "Constitución del Estado libre de Neiva revisada en el año de 1815", AGN, Archivo Academia Colombiana de Historia, Colección Camilo Torres, rollo 1, f. 485; AGN, Sección Archivo Anexo, Fondo Gobierno, t. 19, f. 952r. Véase también Juan Fernández de Sotomayor, Sermón que en la solemne festividad del 20 de Julio, aniversario de la libertad de la Nueva Granada predicó en la Santa Iglesia Metropolitana de Santafé el Ciudadano Dr. Juan Fernández de Sotomayor (Santafé de Bogotá: Imprenta del Ciudadano Bruno Espinosa, 1815), 27-28. 
miembros de la comunidad política, ninguna autoridad puede reclamarse legítima si prescinde de tal consentimiento. Son reconocidas ciertamente unas "obligaciones mutuas del gobierno para con el ciudadano y del ciudadano para con el Gobierno", las cuales constituyen un "contrato" que permite a los ciudadanos reclamar contra los abusos, y al gobierno ejercer plena autoridad para sostenerse contra quienes deseen trastornarlo, como lo advirtió el Presidente de Cundinamarca al momento de ser promulgada la Constitución de esta provincia ${ }^{62}$. Pero esa obligación con respecto al gobierno no era en absoluto incondicionada, pues para que haya propiamente gobierno se requiere infaliblemente la voluntad de los hombres que van a ser gobernados y el respeto de sus derechos por parte del gobierno. Lo escribió Camilo Torres a finales de 1810: “Gobierno legítimo no es, ni puede ser otro, que el que han establecido los mismos hombres para asegurar estos derechos que les dio el cielo, [...] todo abuso contrario a las intenciones de este y de los que lo formaron, es un delito que merece la execración de ambos. Los gobiernos se hacen para los hombres, y no estos para aquellos: por consiguiente, cuando no se ha contado con la voluntad no hay tal gobierno"63. En diversas intervenciones se subrayará que solo mediante un pacto libre y espontáneo puede un hombre ejercer una autoridad justa y legal, la cual, además, no puede dispensar a nadie de la observancia de las leyes. Los ciudadanos, se indicó, no están obligados con el gobierno, "sino a favor de todos los individuos de la sociedad"

Puesto que la autoridad requería tan imperativamente del consentimiento, no podía emerger sino una autoridad precaria. A tal situación contribuyó considerablemente la aspiración manifestada por los revolucionarios de legar a sus descendientes un orden social que estos miraran con respe-

62 "Bando en que se publicó la Constitución, o leyes fundamentales que deben gobernar en el Estado de Cundinamarca", Semanario Ministerial del Gobierno de la Capital de Santafé en el Nuevo Reyno de Granada, No. 15, 23 de mayo de 1811. Una idea similar fue planteada por el editor del periódico Estrella del Occidente en "Antioquia”, Gazeta Ministerial de Cundinamarca, No. 221, Santafé de Bogotá, 4 de mayo de 1815.

63 Camilo Torres, "Continúa la contestación al Reverendo Obispo de Cuenca", Diario Político de Santafé de Bogotá, No. 30, 7 de diciembre de 1810.

64 “Cali”, La Aurora de Popayán, No. 16, Popayán, 12 de junio de 1814; "Variedades. Investigaciones políticas de la Gazeta de la Provincia de Cundinamarca", Argos de la Nueva Granada, No. 95, Santafé de Bogotá, 15 de octubre de 1815. 
to, lo adoptaran y perfeccionaran, pero que no tuvieran que admitir por fuerza. Muchos aceptaron que los hombres, o al menos cada generación, podían romper el pacto constitucional para hacer otro, y subrayaron que la periódica mudanza de gobierno era algo consustancial al nuevo régimen político.

En cuarto lugar, el vínculo social implica ahora una particular especie de obligatoriedad, en el sentido que siendo imprescindible el consentimiento para la creación de la comunidad política, una vez instaurada esta, todos están obligados a acatar sus normas, a contribuir a su mantenimiento y a no hacer nada que la pueda debilitar. Antonio Nariño lo manifestó claramente: "El contrato social es como cualquiera otro contrato: antes de celebrarlo hay una libertad casi indefinida de celebrarlo de este, o el otro modo; pero una vez celebrado, una vez convenido, ya hay una obligación de observarlo por ambas partes, a menos de que haya un vicio notorio y gravísimo en su constitución; y en este caso se reformará por los mismos medios, por el mismo camino que se formó”. Bajo este supuesto, continúa Nariño, "la obediencia y sometimiento al pacto que hemos hecho es una obligación tanto del Público, como de los encargados de su cumplimiento" ${ }^{\prime 6}$. La Junta de la capital neogranadina, de hecho, dio una respuesta perentoria a la pregunta acerca de la suerte que debería correr "el sujeto que no quiera reconocer el nuevo Gobierno": "Se establece por ley, que abandone este individuo nuestra sociedad" ". Los demás gobiernos provinciales también exigieron a sus ciudadanos juramento de fidelidad, no solo a sus respectivas Constituciones sino incluso a ciertas resoluciones gubernativas. En la Provincia de Antioquia, por ejemplo, cuando declararon la independencia absoluta, todos los ciudadanos se vieron obligados a jurarla y se especificó que quienes se negaran serían desterrados, y que

65 Antonio Nariño, “Otra fraternal advertencia al público”, La Bagatela, No. 6, Santafé de Bogotá, 18 de agosto de 1811.

66 "Discurso sobre la organización de poderes en la Suprema Junta de esta Capital de Santafé", Suplemento al número 19 del Diario Político, Santafé de Bogotá, 27 de octubre de 1810. Hubo muchos casos de extrañamiento de la nueva comunidad política. Véase, por ejemplo, el proceso contra Ignacio Vargas, 1810, en AGN, Sección Archivo Anexo, Fondo Justicia, t. 8, f. 648rv. También el castigo impuesto al Doctoral de la Catedral de Santafé, Rafael Lasso de la Vega, en Eduardo Posada, El 20 de Julio (Bogotá: Biblioteca de Historia Nacional, 1914), 237. 
a quienes osaran trastornar el orden social mediante el rechazo a ese juramento, les esperaba la pena de muerte ${ }^{67}$.

No bastaba, sin embargo, con el juramento de aceptación del nuevo orden político. Los ciudadanos fueron llamados a contribuir con sus bienes, sus opiniones, e incluso con su vida, a sostenerlo. De esta manera, el gobierno de la Provincia de Antioquia concluyó a mediados de 1814 que la celebración del "pacto social" o "contrato primitivo" había dado al cuerpo político un derecho indisputable a exigirle a los ciudadanos que contribuyeran con sus bienes a sostenerlo y conservarlo. En el ámbito neogranadino se pensó que los ciudadanos también estaban obligados a no trastornar el orden, pues cuando el hombre consentía en "componer un todo", adquiría el derecho a que la sociedad y cada uno de sus miembros le respetara sus facultades, pero a la vez quedaba obligado a no contribuir al trastorno o disolución de ese todo, y por el contrario debía ayudar a "su cohesión, permanencia, orden, paz y felicidad". De ahí que no fueran considerados como ciudadanos aquellos que injustificadamente se negaran a servir a la Patria y que se ofreciera a cualquier ciudadano la posibilidad de "renunciar las ventajas de la sociedad", emigrando ${ }^{68}$.

En la sociedad democrática que se inaugura en la Nueva Granada, la obligatoriedad de que es revestido el vínculo social es inescindible de su legítima institución y de la intervención de los sujetos en su creación. Esas condiciones fácilmente llevaban al terreno de la controversia, en contraste con la sociedad monárquica, donde la obligatoriedad era enteramente dependiente de la promesa religiosa, la cual le daba una extraordinaria fijeza. La consecuente fragilidad que en adelante caracterizará el vínculo social tiene que ver también con el hecho de que el pueblo solo traspasa sus derechos al poder de manera incompleta. Lo afirmó entre otros el líder revolucionario de la Provincia de Mariquita, José León Armero, para quien "todos los pactos sociales" existen esencialmente en el pueblo, por lo que

67 Acta de independencia de Antioquia, agosto 11 de 1813, en AHJMR, fondo I, Vol. 7, f. 294r.

68 "Decreto del Gobierno", Gazeta Ministerial de la República de Antioquia, No. 5, Medellín, 23 de octubre de 1814; Constitución del Estado de Cartagena, 5, 14-15. A comienzos de 1811 en una parroquia de la Provincia del Socorro se privó a un individuo de la "sociedad civil y política" (AGN, Sección Archivo Anexo, Fondo Justicia, t. 9, f. 118r). 
es un "axioma político" que el pueblo resigna algunos de sus derechos en el gobierno pero se reserva otros para ejercerlos por sí mismo o por medio de sus representantes ${ }^{69}$.

En la forma de gobierno que reunirá a los neogranadinos después de su revolución, el vínculo social siempre irá a aparecer como algo muy frágil, como si fuera inminente la reanudación de la hostilidad primigenia de los hombres. La lucha política tiende a reproducir y a acentuar esa impresión, pero es la que posibilita, al mismo tiempo, que las diferencias de todo orden que caracterizan a la sociedad democrática encuentren un cauce y puedan reanudar la tregua. Un cura lealista deploró en 1816 la democracia que se había dado en la Nueva Granada porque ella era por definición "un volcán que siempre vomita fuegos, y estragos”, porque "jamás reposa aunque pasen los siglos", porque es "una continua insurrección del pueblo" y, en ella, el mérito es más peligroso que el delito mientras que la justicia es reemplazada por la violencia y la intriga ${ }^{70}$.

\section{CONCLUSIÓN: FoRMA DE GOBIERNO Y VÍNCULO SOCIAL}

En el conjunto de las revoluciones del mundo hispánico, la Revolución Neogranadina presentó un carácter particularmente rupturista, en el sentido que los principios que hizo prevalecer entrañaban de por sí una profunda brecha respecto a los principios que habían organizado la sociedad mientras estuvo articulada en torno al poder monárquico. Desde entonces el vínculo social fue imaginado de una manera completamente distinta y, desde entonces tomaron forma experiencias inéditas de la coexistencia entre los hombres. Como partícipes de la ciencia política de su época, los publicistas neogranadinos de todo el periodo abordado en este artículo consideraron que el vínculo social era impensable por fuera del régimen

69 Representación al Senado de Cundinamarca, julio 14 de 1812, en José Vicente París, "Vida del licenciado Don José León Armero”, Boletín de Historia y Antigüedades, año X, No. 110 (1915): 71.

70 Nicolás de Valenzuela y Moya, Oración gratulatoria y parenética, pronunciada el día 10 de septiembre de 1816 en la Parroquial de la Ciudad de Neiva, ante el Consejo de Guerra del Ejército Expedicionario, y solemne concurso en acción de gracias por el feliz éxito de las Armas Reales en la reconquista del Nuevo Reino de Granada (Santafé de Bogotá: Imprenta del Superior Gobierno, 1817). 
político. Ya fuera la monarquía o la república, la forma de gobierno constituía el marco ineludible en el cual los hombres se ponían en contacto. Esta no impone al vínculo social unas determinaciones minuciosas, ni tampoco instaura unos diques que no puedan ser franqueados en algún momento, pero le da un campo específico de posibilidades, le da un canon que sugiere dónde está lo justo y lo loable.

La conexión directa que durante este periodo fue establecida entre vínculo social y régimen político remite a una perspectiva en la que lo político es axial, en la que lo político posee un carácter instituyente que las mutaciones de la democracia y de los estudios políticos tendieron a desvalorizar.

\section{BibliografíA}

\section{Fuentes primarias}

\section{Archivo}

Archivo General de Indias (AGI), Sevilla, Estado, 53, 57.

Archivo General de la Nación (AGN), Bogotá, Archivo Academia Colombiana de Historia, Colección Camilo Torres, rollo 1.

Archivo General de la Nación (AGN), Bogotá, Sección Archivo Anexo, Fondo Justicia, t. 8, 9.

Archivo General de la Nación (AGN), Bogotá, Sección Archivo Anexo, Fondo Historia, t. 12.

Archivo General de la Nación (AGN), Bogotá, Sección Archivo Anexo, Fondo Gobierno, t. 19.

Archivo General de la Nación (AGN), Bogotá, Sección Colonia, Colegios, t. 2.

Archivo General de la Nación (AGN), Bogotá, Sección Colonia, Genealogías, rollo 13.

Archivo Histórico Javeriano (AHJ), Bogotá, Fondo Camilo Torres, carpetas $79,89$.

Archivo Histórico José Manuel Restrepo (AHJMR), Bogotá, fondo I, vols. 4,7 .

Archivo Histórico Municipal de Cali, Fondo Cabildo, t. 38.

Biblioteca Nacional, Bogotá. Fondo Pineda 184 y Manuscritos, RM435. 


\section{Publicaciones periódicas}

Argos de la Nueva Granada, Santafé de Bogotá, 1815.

Correo Curioso, Erudito Económico y Mercantil, Santafé de Bogotá, 1801.

Diario Político de Santafé de Bogotá, Santafé de Bogotá, 1810.

El Argos Americano, Cartagena, 1811.

El Español, Londres, 1812.

El Republicano, Tunja, 1815.

Gazeta Ministerial de Cundinamarca, Santafé de Bogotá, 1813-1815.

Gazeta Ministerial de la República de Antioquia, Medellín, 1814.

La Aurora de Popayán, Popayán, 1814.

La Bagatela, Santafé de Bogotá, 1811.

Papel Periódico de la Ciudad de Santafé de Bogotá, 1791-1796.

Semanario Ministerial del Gobierno de la Capital de Santafé en el Nuevo Reyno de Granada, 1811.

\section{Libros y documentos impresos}

"Constitución de la Provincia de Popayán". Boletín Histórico del Valle, No. 49-53 (1938): 40-51.

Actas del Serenísimo Colegio Constituyente y Electoral de la Provincia de Cundinamarca. Congregado en su capital la ciudad de Santafé de Bogotá para formar y establecer su Constitución. Santafé de Bogotá: Imprenta Real, 1811.

Carta pastoral del Ilmo. y Rmo. Señor D. Fr. Adeodato Turchi del orden de capuchinos. Valencia: Impreso por Martín Antonio Peris, 1790.

Constitución de la República de Tunja. Santafé de Bogotá: Imprenta de D. Bruno Espinosa, 1811.

Constitución del Estado de Cartagena de Indias, sancionada en 14 de junio del año de 1812. Cartagena: Imprenta del Ciudadano Diego Espinosa, 1812.

Constitución provisional de Antioquia, revisada en Convención de 1815. Medellín: Imprenta del Gobierno, 1815.

Consulta de Doña Ángela Isidra del Campo a Don Felipe de Vergara, y su respuesta sobre ¿si en Santafé de Bogotá será, o no lícito cenar la Noche buena, y cenar buñuelos y pescado?, [1799]. Bogotá: Instituto Caro y Cuervo, 1993. 
De Finestrad, Joaquín. El vasallo instruido. Bogotá: Universidad Nacional, 2000.

De Pombo, Miguel. Constitución de los Estados Unidos de América. Santafé de Bogotá: Imprenta Patriótica, 1811.

De Torres y Peña, José Antonio. Memorias del Presbítero José Antonio de Torres y Peña. Bogotá: Editorial Kelly, 1960.

De Torres y Peña, José Antonio. Viva Jesús. La voz de la religión, contra el papel sacrílego, que con agravio de lo más sagrado se titula falsamente: la voz de la verdad. Santafé de Bogotá: Imprenta de Jesús, 1813.

De Valenzuela y Moya, Nicolás. Oración gratulatoria y parenética, pronunciada el día 10 de septiembre de 1816 en la Parroquial de la Ciudad de Neiva, ante el Consejo de Guerra del Ejército Expedicionario, y solemne concurso en acción de gracias por el feliz éxito de las Armas Reales en la reconquista del Nuevo Reino de Granada. Santafé de Bogotá: Imprenta del Superior Gobierno, 1817.

Edicto para manifestar al público el indulto general, concedido por nuestro Católico Monarca el Sr. D. Carlos III a todos los comprendidos en las revoluciones acaecidas en el año pasado de mil setecientos ochenta y uno. Santafé de Bogotá: s.e., 1782.

Fernández de Sotomayor, Juan. Sermón que en la solemne festividad del 20 de Julio, aniversario de la libertad de la Nueva Granada predicó en la Santa Iglesia Metropolitana de Santafé el Ciudadano Dr. Juan Fernández de Sotomayor. Santafé de Bogotá: Imprenta del Ciudadano Bruno Espinosa, 1815.

Florido, Francisco. Sermón que en la fiesta de Santa Librada hecha en obsequio del Excmo. Señor Presidente Don Antonio Nariño por el Ilustre Cabildo de la Villa de Bogotá, pronunció el P. L. Francisco Florido de la Orden de San Francisco. Santafé de Bogotá: Imprenta de D. Bruno Espinosa, 1812.

Índice último de los libros prohibidos y mandados expurgar: para todos los reynos y señoríos del Católico rey de las Españas. Madrid: Imprenta de Don Antonio de Sancha, 1790.

Julián, Antonio. Monarquía del diablo en la gentilidad del Nuevo Mundo americano [1790]. Bogotá: Instituto Caro y Cuervo, 1994.

Reglamento para el gobierno provisorio de la Provincia de Pamplona. Tunja: Imprenta del Estado, 1815. 
Relación de las Providencias que se han dado por el MIC de Cartagena de Indias. Cartagena: Imprenta del Real Consulado, 1810.

Villanueva, Joaquín Lorenzo. Catecismo del estado según los principios de la religión. Madrid: Imprenta Real, 1793.

\section{Fuentes secundarias}

"Preludios de la revolución de los comuneros en el Perú". Revista del Archivo Nacional, Año III Nos. 20/21 (1938): 4, 7-8.

Bancal, Henry. Du nouvel ordre social. París: Imprimerie du Cercle Social, 1792.

Corrales, Manuel Ezequiel. Documentos para la historia de la Provincia de Cartagena de Indias, hoy Estado Soberano de Bolívar en la Unión Colombiana, T. I. Bogotá: Imprenta de Medardo Rivas, 1883.

Díaz, Oswaldo. Copiador de órdenes del Regimiento de Milicias de Infantería de Santafé (1810-1814). Bogotá: Fuerzas Armadas, 1963.

Friede, Juan. Rebelión comunera de 1781. Documentos, T. II. Bogotá: Instituto Colombiano de Cultura, 1982.

Gómez Hoyos, Rafael. “Un ensayo manuscrito de 1800”. Boletín de Historia y Antigüedades, Vol. XLIX Nos. 567, 568, 569 (1962): 86.

Gredilla, Apolinar Federico. Biografía de José Celestino Mutis con la relación de viaje y estudios practicados en el Nuevo Reino de Granada. Madrid: Establecimiento Tipográfico de Fortanet, 1911.

Gutiérrez, Daniel. Las asambleas constituyentes de la independencia. Bogotá: Corte Constitucional/Universidad Externado, 2010.

Gutiérrez, Jairo y Armando Martínez. La visión del Nuevo Reino de Granada en las Cortes de Cádiz (1810-1813). Bogotá: Academia Colombiana de Historia/UIS, 2008.

Hernández, Guillermo. Documentos para la historia de la educación, T. VII. Bogotá: Patronato Colombiano de Artes y Ciencias, 1986.

Hernández, Guillermo. Documentos para la historia de la educación, T. V. Bogotá: Editorial Kelly, 1983.

Jaramillo, Jaime. Ensayos de historia social, T. I. Bogotá: Tercer Mundo/ Uniandes, 1994.

Lamennais, Félicité Robert. Des progrès de la Révolution et de la guerre contre l'Église. Lovaina: Vanlinthout et Vandenzande, 1829. 
Lamy, Bernard. Entretenimiento sobre las ciencias, T. I. Madrid: Oficina de Benito García, 1800.

Lucena, Manuel. El memorial de Don Salvador Plata. Bogotá: Instituto Colombiano de Cultura Hispánica, 1982.

Monteagudo, María Pilar. La Monarquía ideal. Imágenes de la realeza en la Valencia moderna. Valencia: Universitat de València, 1995.

Paine, Thomas. La Independencia de la Costa Firme justificada por Thomas Paine treinta años ha. Filadelfia: Imprenta de T. y J. Palmer, 1811.

París, José Vicente. "Vida del licenciado Don José León Armero. Boletín de Historia y Antigüedades, Año X No. 110, (1915): 71-73.

Pérez, José Manuel. Causas célebres a los precursores, T. I. Bogotá: Imprenta Nacional, 1939.

Posada, Eduardo. El 20 de Julio. Bogotá: Biblioteca de Historia Nacional, 1914.

Twinam, Ann. Vidas públicas, secretos privados. Género, honor, sexualidad e ilegitimidad en la Hispanoamérica colonial. Buenos Aires: Fondo de Cultura Económica, 2009.

Vanegas, Isidro. La Revolución Neogranadina. Bogotá: Ediciones Plural, 2013.

Vanegas, Isidro. "Los inicios del régimen democrático en la Nueva Granada: la noción y sus dilemas (1790-1830)". Historia Crítica, No. 58 (2015): 57-75.

Para citar este artículo: Vanegas Useche, Isidro. "El vínculo social en Nueva Granada 1780-1816”, Historia Caribe Vol. XI No. 28 (Enero-Junio 2016): 17-49. DOI: http://dx.doi.org/10.15648/hc.28.2016.2 